\title{
Correction to: Anatomical variations in the origins of the celiac axis and the superior mesenteric artery: MDCT angiographic findings and their probable embryological mechanisms
}

\author{
Yi Wang ${ }^{1} \cdot$ Cheng Cheng ${ }^{1} \cdot$ Lu Wang $^{1} \cdot$ Ran $^{\mathrm{Li}^{1}}{ }^{1}$ Jin-hua Chen ${ }^{1} \cdot$ Shui-gen Gong ${ }^{1}$ \\ Published online: 13 June 2019 \\ (C) European Society of Radiology 2019
}

Correction to: Eur Radiol (2014) 24:1777-1784

https://doi.org/10.1007/s00330-014-3215-9

The original version of this article, published on 24 May 2014, unfortunately contained a referencing omission. Figure $5 \mathrm{~b}, \mathrm{~d}$, and $\mathrm{f}$ were based on Fig. 4 of Song et al [1]. The Radiological Society of North America has kindly provided retroactive permission to use a modified version of the image.

\section{References}

1. Song SY, Chung JW, Yin YH et al (2014) Celiac axis and common hepatic artery variations in 5002 patients: systematic analysis with spiral CT and DSA. Radiology 255:278-288

Publisher's note Springer Nature remains neutral with regard to jurisdictional claims in published maps and institutional affiliations.

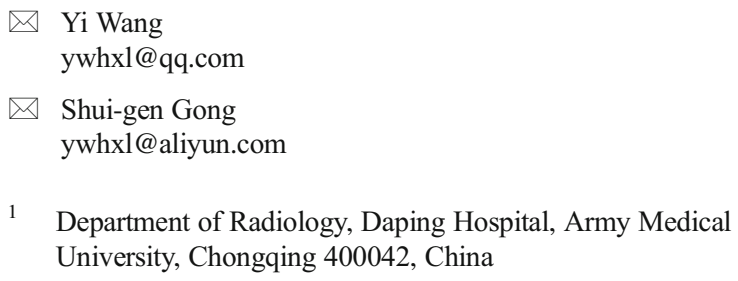

